\title{
PERANCANGAN ENTERPRISE ARCHITECTURE PADA PT.GADINGPUTRA SAMUDRA MENGGUNAKAN FRAMEWORK TOGAF ADM
}

\author{
Jason Steven Antouw1), Johanes Fernandes Andry²) \\ ${ }^{1,2}$ Sistem Informasi, Universitas Bunda Mulia \\ 1,2 JL.Lodan Raya No.2 , Jakarta Utara

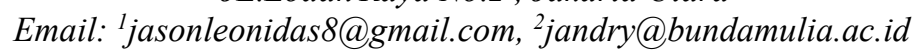

\begin{abstract}
Present offshore services are very important in the context of distributing imports and exports of goods. because it requires services that allow companies to help with the use of ships. PT Gadingputra Samudra provides offshore services such as Crewing, Agency, Logistics, and Broking. At present the company can carry out the contract in accordance with the requirements and is able to complete the contract well but the company's business processes have some weaknesses because the system is not yet integrated and there is no automatic storage system. The Open Group Architecture Framework (TOGAF) was chosen as a method for analyzing. by using the Architecture development method (ADM) which focuses on business architecture. in this analysis the expected outcome is to integrate information systems and information technology with business processes to be in line and be able to help the company's business processes to obtain optimal, effective and efficient business processes.
\end{abstract}

Keywords: TOGAF ADM, Offshore, PT. Gadingputra Samudra

\begin{abstract}
Abstrak
Saat ini layanan lepas pantai sangat penting dalam konteks mendistribusikan impor dan ekspor barang. karena itu membutuhkan layanan yang memungkinkan perusahaan untuk membantu dengan penggunaan kapal. PT Gadingputra Samudra menyediakan layanan lepas pantai seperti Crewing, Agency, Logistik, dan Broking. Saat ini perusahaan dapat melaksanakan kontrak sesuai dengan persyaratan dan mampu menyelesaikan kontrak dengan baik tetapi proses bisnis perusahaan memiliki beberapa kelemahan karena sistemnya belum terintegrasi dan belum ada sistem penyimpanan otomatis. The Open Group Architecture Framework (TOGAF) dipilih sebagai metode untuk menganalisis. dengan menggunakan metode pengembangan Arsitektur (ADM) yang berfokus pada arsitektur bisnis. dalam analisis ini hasil yang diharapkan adalah mengintegrasikan sistem informasi dan teknologi informasi dengan proses bisnis agar sejalan dan dapat membantu proses bisnis perusahaan untuk mendapatkan proses bisnis yang optimal, efektif dan efisien.
\end{abstract}

Kata Kunci: TOGAF ADM, Offshore, PT.Gadingputra Samudra

\section{Pendahuluan}

Perkembangan zaman pada saat ini berperan besar pada proses bisnis perusahaan karena itu dalam mendukung proses bisnis perusahaan sistem informasi dan teknologi informasi di implementasikan dalam skala yang besar untuk meningkatkan kinerja dalam suatu perusahaan [1]. Teknologi sistem informasi digunakan untuk mencapai tujuan dan misi pada perusahaan penggunaan nya tidak hanya untuk proses otomatisasi terhadap akses informasi, tetapi juga menciptakan kecepatan, keakuratan dan kelengkapan dalam sebuah sistem yang terintegrasi [2].

PT. Gadingputra Samudra yang selanjutnya akan di panggil dengan sebutan PT.GS didirikan pada tahun 2012 tujuan dari perusahaan adalah untuk menciptakan nilai baru untuk memenuhi harapan Stakeholder.PT GS menyediakan layanan Sea Offshore dengan kapal yang sudah sesuai persyaratan untuk perusahaan oli dan gas, kontraktor pengeboran, Surveyor dan Subsea Companies [3].

Penggunaan IT pada saat ini sangat berperan besar dalam membantu prose bisnis dalam perusahaan dalam mendukung pencapaian tujuan dan visi dan misi perusahaan. dengan ada nya pengimplementasian IT dalam perusahaan dapat menciptakan sinergi dan integritas perusahaan [4], [5]. Saat ini belum ada pengimplementasian sistem aplikasi pada bagian management yang memungkinkan para Stakeholder untuk menyimpan informasi perusahaan yang dapat mengurangi human error dan bisa membantu para stakeholder dalam melakukan penyimpanan data yang lebih aman dan lebih efektif dan pada saat ini belum ada nya sistem aplikasi yang mampu mempermudah bagian Keuangan dalam membantu proses bisnis dalam perusahaan yang diperlukan untuk melakukan pendataan dan juga pada divisi purchasing belum ada nya aplikasi yang mampu melakukan penyimpanan data [6]. Dalam rencana 
pengimplementasian sistem terintegrasi pada PT.GS perlu melakukan perencanaan pengembangan cetak biru.

Pada penelitian ini dilakukan focus pada membentuk perencanaan pengembangan cetak biru aplikasi sebagai pedoman organisasi untuk melakukan pengembangan IT dalam proses bisnis perusahaan agar bisa membantu para stakeholder dalam perusahaan dan juga agar bisa membantu perusahaan untuk berkembang menjadi lebih maju dan sesuai dengan visi dan misi yang dituju [7]. Tujuan integrasi yang sebenarnya adalah unutk menutupi kesenjangan yang terjadi dalam proses untuk menurunkan kesenjangan tersebut maka diperlukanlah suatu Blueprint dalam merencanakan, merancang, dan mengelola sistem informasi karena itu dibutuhkan suatu perencanaan Enterprise Architecture yang mampu menyediakan framework yang akan diggunakan sebagai acuan dalam pengembangan sistem informasi salah satunya adalah TOGAF (The Open Group Architecture Framework) [8]. Dengan diadakan nya penelitian ini di harapkan perusahaan dapat meningkatkan efektifitas dan efisiensi kerja dalam proses bisnis nya dan terintegrasi nya sistem perusahaan yang dapat menunjang proses bisnis perusahaan

\section{Tinjauan Pustaka}

\section{Enterprise Architecture}

Enterprise Architecture adalah sebuah masterplan yang bertidak sebagai kolaborator dari beberapa aspek diantara nya aspek perencanaan bisnis seperti tujuan, visi, misi, dan prinsip tata kelola yang baik. Dalam membantu proses bisnis perusahaan masterplan dapat membantu dalam perencanaan struktur organisasi, tugas dan kegiatan perusahaan pada aspek komputerisasi seperti sistem informasi dan database, dan infrastruktur teknologi yang mendukung bisnisnya seperti computer, jaringan dan sistem operasi [9].

\section{TOGAF}

The Open Group Architecture Framework (TOGAF) adalah suatu framework yang suatu framework yang banyak digunakan dalam pengembangan aristektur perusahaan TOGAF menyediakan metode dan tools untuk membangun, mengelola dan mengimplementasikan serta pemeliharaan arsitektur enterprise dan sistem informasi.

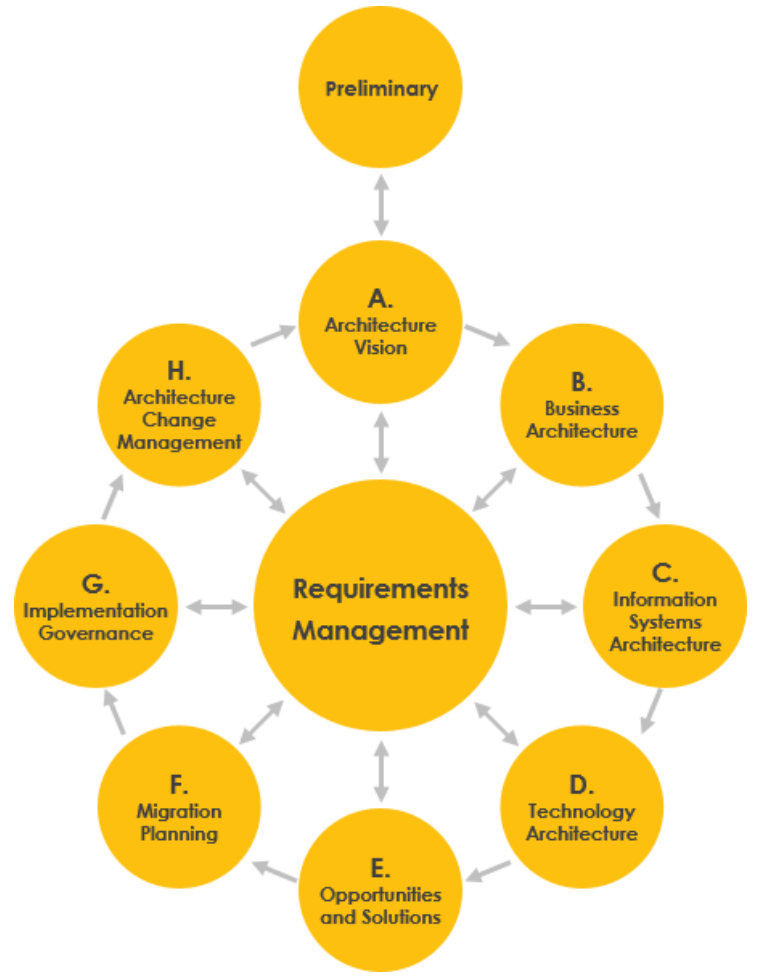

Gambar 1. Fase ADM [11]

Elemen penting dari TOGAF adalah Architecture Development Method (ADM) yang menjelaskan secara detail proses bisnis perusahaan dan menentukan kebutuhan Enterprise Architecture sesuai dengan kebutuhan. Siklus pengembangan TOGAF ADM merupakan metodologi logis yang terdiri dari delapan fase utama untuk pengembangan dan pemeliharaan yang terdiri dari business architecture, data architecture, application architecture, dan technical architecture dari organisasi[9]. Pada Gambar 1 Fase ADM menjelaskan Fase TOGAF ADM [10].

- Preliminary Phase - dalam fase ini menjelaskan aktivitas persiapan untuk menentukan ruang lingkup arsitektur TOGAF dan mendefinisikan struktur organisasi dalam perusahaan.

- Phase A: Architecture Vision - fase ini menguraikan kondisi infrastruktur TI dalam perusahaan dan mengidentifikasikan Stakeholder, visi dan misi dalam perancangan arsitektur

- Phase B: Business Architecture - dalam fase ini menguraikan pengembangan arsitektur bisnis yang telah di definisikan dalam visi arsitektur yang akan diggunakan dalam pmengembangkan proses bisnis perusahaan.

- Phase C: Information System Architecture - Pada tahapan ini mengembangkan sistem informasi mandiri yang di kembangkan berdasarkan kebutuhan perusahaan.

- Phase D: Technology Architecture - Menentukan teknologi dan perangkat lunak yang akan digunakan dalam membantu pengimplementasian teknologi informasi dalam perusahaan 
- Phase E: Opportunities and Solutions - dalam tahapan ini menjabarkan hasil pembentukan Blueprint dari Information System Architecture sampai Technology Architecture untuk menganalisa gap antara system lama dan system baru

- Phase F: Migration Planning - Pada fase ini akan dilakukan analisis resiko dan biaya

- Phase G: Implementation Governance - fase ini menganalisa keefektifan dan efisiensi dari pengimplementasian system yang telah dibangun .

- Phase H: Architecture Change Management - pada fase ini melakukan penyusunan prosedur - prosedur yang akan diggunakan untuk menjalankan system baru yang telah dibuat

- Requirement Management - menguji proses pengelolaan architecture requirements sepanjang siklus ADM berlangsung.

\section{Value Chain}

Analisis rantai nilai (Value Chain) adalah alat strategi yang digunakan untuk menganalisis kegiatan internal perusahaan. Tujuan digunakannya value chain adalah untuk mendefinisikan kegiatan utama dan kegiatan pendukung dalam proses bisnis perusahaan dan mana yang dapat ditingkatkan untuk memberikan keunggulan kompetitif. Dengan kata lain, dengan melihat ke dalam kegiatan internal, analisis mengungkapkan di mana keunggulan kompetitif atau kerugian perusahaan. Perusahaan yang bersaing melalui keunggulan diferensiasi akan mencoba melakukan kegiatannya lebih baik daripada yang dilakukan pesaing. Jika bersaing melalui keunggulan biaya, ia akan mencoba melakukan kegiatan internal dengan biaya lebih rendah daripada pesaing. Ketika sebuah perusahaan mampu menghasilkan barang dengan biaya lebih rendah dari harga pasar atau untuk menyediakan produk-produk unggulan, itu menghasilkan keuntungan [12]. Rantai nilai ini menjelaskan aktivitas perusahaan menjadi dua jenis aktivitas, seperti [13]:

- Primary Activities - berkaitan langsung dengan menciptakan dan mengirimkan produk. Mereka dapat dikelompokkan ke dalam lima bidang utama yaitu

○ Inbound Logistic

- Outbound

- Logistics

- Marketing and Sales

- Service

- Support Activities - Support Activities membantu kegiatan utama dalam membantu organisasi mencapai keunggulan kompetitifnya. Ada empat bidang utama kegiatan pendukung yaitu :
- Firm Infrastructure
- Human Resource Management
- Technology Development
- Procurement

\section{Metode Peneltian}

Pada Gambar 2. Metode Penelitian, dilakukan dengan menggunakan metode kualitatif instrumen pengambilan data yang dipilih adalah wawancara, dan observasi.

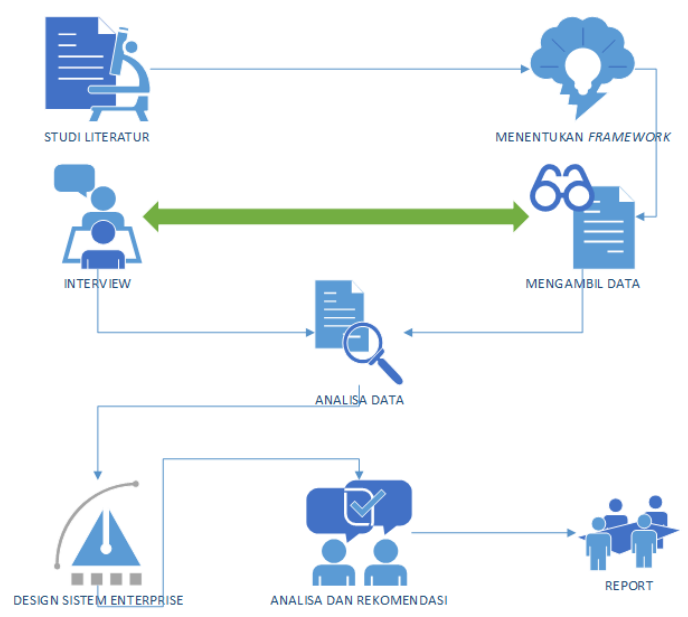

Gambar 2. Metode penelitian [14]

Dengan menggunakan instrument tersebut penulis bisa menggumpulkan data dengan secara menyeluruh dan penulis bisa melihat langsung proses bisnis yang saat ini terjadi pada organisasi [15], berikut ini adalah proses interview dan observasi yang akan dilakukan:

Langkah pertama dalam penelitian ini adalah melakukan studi penelitian terdahulu yang berhubungan dengan kasus yang dialami oleh penulis saat ini setelah melakukan studi literature penulis menentukan framework apa yang cocok digunakan dalam kasus ini penulis memilih framework TOGAF.

Setelah itu penulis mulai proses pengambilan data.pengambilan data bisa dilakukan dengan cara observasi proses bisnis yang berjalan di dalam organisasi. setelah itu penulis melakukan interview kepada stakeholder yang memegang peranan penting dan menguasai proses bisnis dalam perusahaan.

Setelah itu penulis menganalisa data yang didapat dari interview dan observasi untuk bisa membuat perancangan arsitektur. Setelah perancangan sberhasil dibuat penulis akan membuat hasil analisa yang berupa rekomendasi dan analisa berdasarkan rancangan enterprise yang dibuat dan memberikan nya kepada perusahaan [14].

\section{Pembahasan}

\section{Preliminary Phase}

Tahapan ini adalah tahapan awal yang merupakan tahapan persiapan dalam melakukan perencanaan arsitektur enterprise. Dalam tahapan ini mendeskripsikan aktivitas inisiasi dan persiapan untuk bisa memenuhi requirement agar perencanaan Enterprise Architecture 
dapat berjalan sesuai dengan proses bisnis dan prosedur perusahaan.

PT.Gadingputra Samudra sebagai suatu perusahaan Offshore yang sedang berkembang pada saat ini dan juga melihat permintaan client yang semakin tinggi di dalam perusahaan. harus sadar akan pentingnya implementasi sistem informasi dan teknologi informasi di dalam perusahaan nya dengan mengitegrasikan sistem perusahaan dengan rencana strategi SI/TI. Agar perusahaan bisa mencapai visi dan misi dan tujuan perusahaan. perusahaan harus bisa mengandalkan SI dan TI sebagai pendukung proses bisnis perusahaan. Dengan adanya perancangan Enterprise Architecture akan dibuatkan sebuah pedoman atau Blueprint. Dalam melakukan perancangan ini metode yang digunakan adalam menggunakan TOGAF ADM yang menggunakan 5 fase yaitu :

- Architecture Vision

- Business Architecture

- Information System Architecture

- Technology Architecture

- Opportunities and Solutions

Untuk mengidentifikasi aktivitas - akivitas utama dan pendukung, maka Value Chain perlu diggambarkan untuk menggambarkan kegiatan - kegiatan dalam perusahaan dan sebagai acuan untuk meningkatkan Value perusahaan. Berikut ini adalah penjelasan aktivitas utama dan pendukung pada PT.Gadingputra Samudra.

\section{Main Activities}

- Inbound Logistic - Mendapatkan tender dari perusahaan yang membutuhkan jasa yang berhubungan dengan Offshore dan Logistic

- Operations - Ada beberapa jasa yang ditawarkan oleh perusahaan yaitu Agency, Broking, Logistic, Crewing, Survey

- Outbound Logistic - Mencari sebuah kapal yang sesuai dengan kualifikasi tender

- Marketing and Sales - Mencari tender, memasarkan jasa dan menjalin relasi terhadap perusahaan perusahaan

\section{Support Activities}

- Firm Infrastructure - terdapat 3 divisi yang membantu perusahaan dalam mengalokasikan keuangan , pembelian, pembukuan yaitu Acoounting, Purchasing dan Finance

- Human Resource Management - HR bertanggung jawab dalam melakukan perekrutan karyawan, memantau kinerja karyawan dan Training karyawan

- Technology Development - dalam membantu proses bisnis perusahaan menggunakan alat bantu perangkat keras Komputer, Printer dan alat bantu perangkat lunak Microsoft Word dan Microsoft Excel
- Procurement - Mendapatkan harga bid kapal terbaik karena memiliki relasi yang bagus dengan perusahaan kapal di asia tenggara

\section{Architecture Vision}

Pada tahapan ini berisi tentang visi, misi dan tujuan bisnis dan struktur organisasi, hal ini didapatkan dari proses observasi didalam kantor dan melakukan wawancara pada Stakeholder. Berdasarkan observasi dan wawancara pada Stakeholder perusahaan didapatkan untuk menujang proses bisnis perusahaan dibutuhkan perancangan SI/TI yaitu :

- Memberikan layanan untuk meningkatkan dan membangun hubungan kerja sama jangka panjang dengan mitra bisnis

- Merancang Blueprint Architecture Enterprise sebagai acuan untuk perusahaan dalam membantu proses bisnis nya

- Membangun sistem data yang terintegrasi pada setiap bagian divisi di dalam perusahaan

- Membangun sistem Sharing Data antara divisi untuk mempermudah divisi dalam pengiriman data

- Mampu membentuk sistem terintegrasi yang cepat dan akurat di dalam perusahaan

\section{Bussiness Architecture}

Pada tahapan ini di analisis proses bisnis yang berjalan pada PT.Gadingputra Samudra. Secara garis besar PT.Gadingputra Samdura pada saat ini adalah memberikan pelayanan seperti Agency, Broker, Logistic, Crewing, Management dan Survey. Berdasarkan observasi yang dilakukan pada PT.Gadingputra Samudra proses bisnis hampir semua kegiatan - kegiatan yang dilakukan masih di proses dengan metode manual. Sebagai contoh disaat divisi QHSE perlu untuk melihat Procedure atau SOP karyawan harus melihat Logbook yang tidak efisien dalam pencarian data melihat data yang terdapat di bagian QHSE sangat banyak.

Dalam proses bisnis nya divisi keuangan belum terintegrasi satu sama lain nya karena ha ini divisi keuangan belum efektif dalam melakukan penginputan data dan penyimpanan data. Human Error masih sering terjadi dalam penginputan data dan penyimpanan data sebagai contoh data yang hilang karena penyimpanan data yang masih tersimpan dalam Harddisk. dan tidak selarasnya data antara divisi keuangan yang menyebabkan kesalahan data dan harus melakukan penginputan data kembali untuk menyelaraskan data tanpa adanya sistem terintegrasi

Divisi keuangan terdiri dari Finance, Purchasing dan Accountng dalam perusahaan divisi-divisi tersebut harus saling terintegrasi karena informasi yang dihasilkan harus cocok satu sama lain pada bagian Purchasing bertugas untuk melakukan pembelian kebutuhan perusahaan dan kebutuhan - kebutuhan proyek yang sedang berjalan. Pada bagian Finance bertugas untuk melakukan pengelolaan 
keuangan perusahaan dan melakukan pembayaran yang berhubungan dengan hukum karena hal ini data keuangan harus selaras dengan Purchasing agar data yang dihasilkan Valid. Dan pada bagian Accounting bertugas untuk melakukan pencatatan keuangan dalam hal ini Accounting tidak berhubungan langssung pada kas perusahaan tetapi Accounting bertugas unutk melakukan laporan keuangan dan mencatat transaksi bisnis perusahaan. Karean hal ini Accounting harus membuat pencatatan data dari Purchasing dan Finance karena hal itu data harus lah Valid agar tidak terjadi kesalahan pencatatan data yang dapat merugikan perusahaan

Sesuai dengan gambaran Value Chain yang digambarkan sebelumnya, maka Main Activity dan Support Activity penggambaran Workflownya dapat diidentifikasikan proses bisnis secara keseluruhan dengan menggunakan Rich Picture sebagai berikut ini :

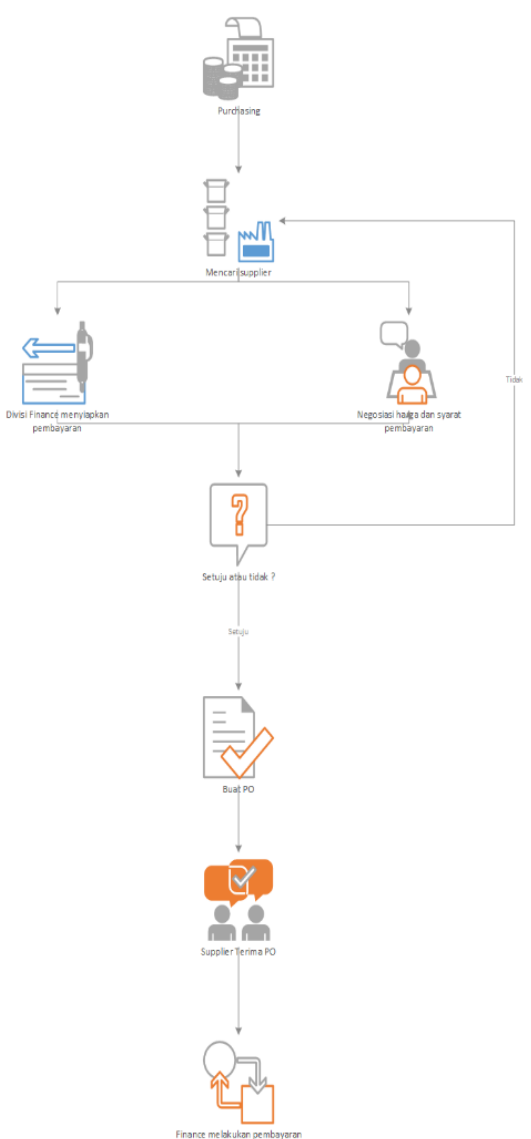

Gambar 3. Workflow Purchasing

Pada tahapan ini yang digambarkan pada Gambar 3 Workflow Purchasing, dijelaskan tentang bagaimana Purchasing melakukan proses pembelian barang yang diperlukan perusahaan dalam menunjang proses bisnis nya. Purchasing melakukan pencarian supplier yang di perlukan perusahaan setelah mendapatkan Supplier Purchasing melakukan negosiasi harga dan syarat pembayaran yang harus dipenuhi jika persyaratan dan harga disetujui Purchasing akan mengajukan pembuatan PO ke Finance setelah PO di setujui bagian Purchasing akan mengirimkan PO dan menerima barang yang dibutuhkan sesuai dengan harga yang disetujui dan persyaratan yang harus dipenuhi.

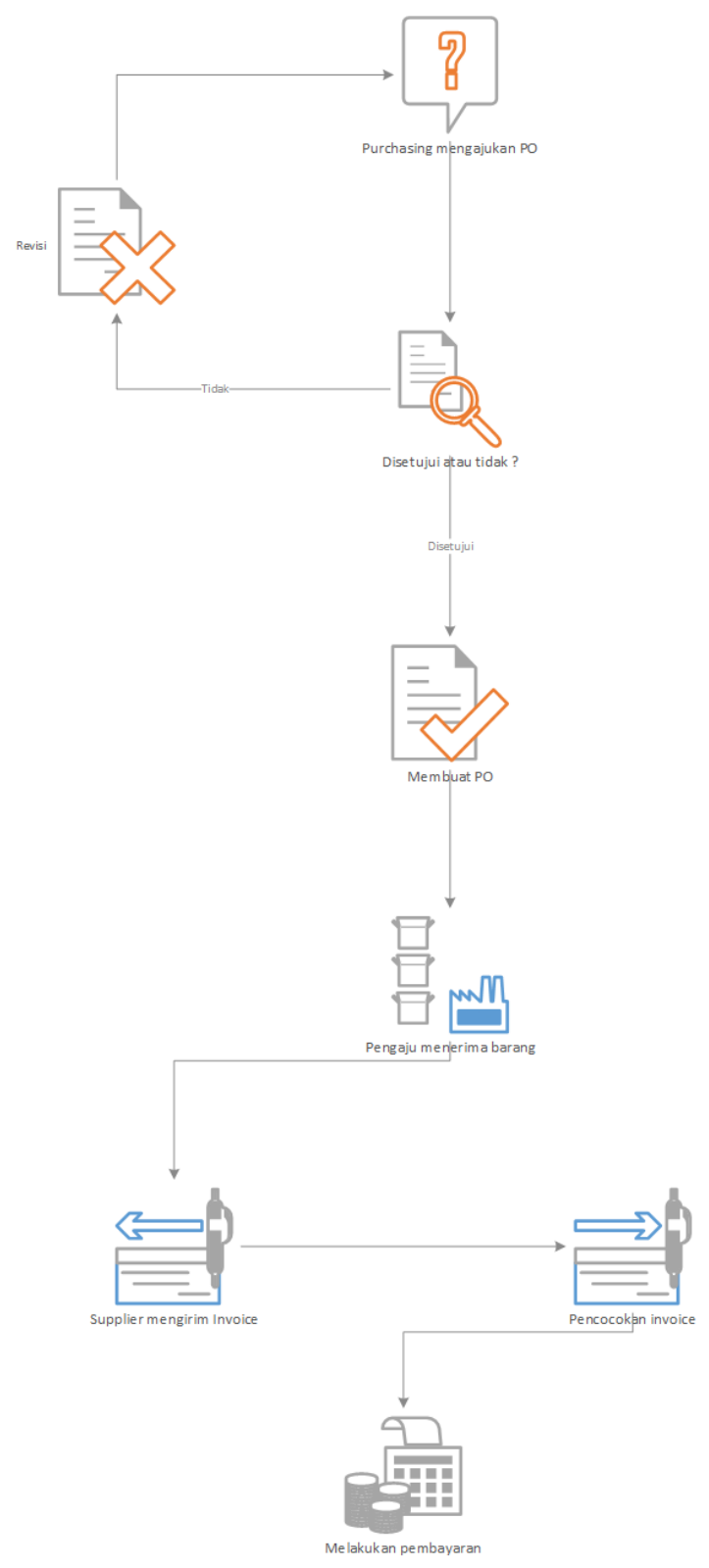

Gambar 4. Workflow Finance

Pada tahapan ini yang digambarkan pada Gambar 4. Workflow Finance, akan dijelaskan proses bisnis dalam divisi Finance. Divisi ini berhubungan langsung dengan Purchasing dalam melakukan persetujuan pengeluaran keuangan perusahaan dan pengelolaan kas perusahaan. pada tahapan pembeliannbarang Finance melakukan pemeriksaan barang yang akan dibeli, harga barang dan persyaratan barang jika harga barang dan persyaratan pembayaran disetujui divisi Finance membuatkan PO yang akan dikirimkan oleh divisi Purchasing. Setelah barang diterima oleh pengaju Invoice akan diterima oleh Finance dan dilakukan pencocokan barang dan harga.jika barang dan harga sesuai Finance akan melakukan pembayaran sesuai dengan persyaratan yang disetujui. 


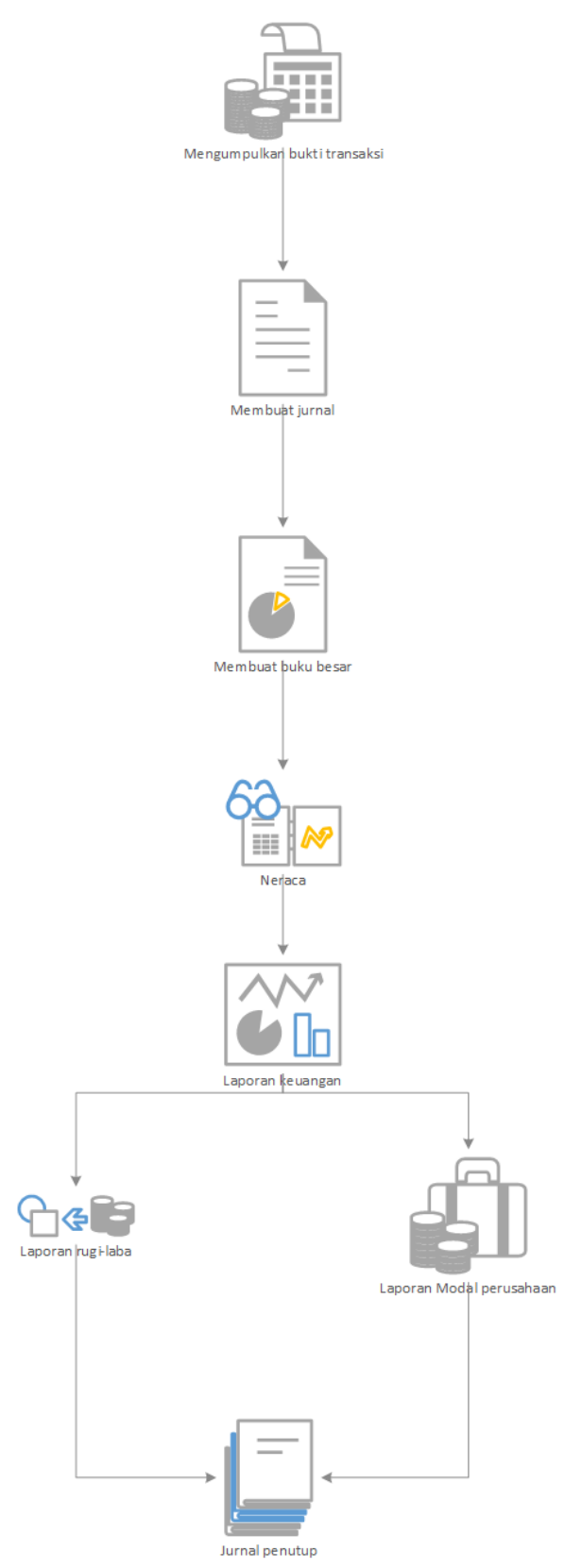

Gambar 5. Workflow Accounting

Pada tahapan yang diggambarkan pada Gambar 5 . Workflow Accounting menjelaskan proses kerja pada divisi Accounting. Divisi ini bertanggung jawab dalam pencatatan transaksi, pembelian dan pengelolaan uang dalam perusahaan. divisi mengumpulkan data pada bagian Finance dan pada bagian Purchasing. Setelah data di validasi Accounting membuat jurnal keuangan yang akan di jadikan acuan dalam pembuatan neraca dan pembuatan buku besar perusahaan. setelah data telah di catat dan sudah terverifikasi kecocokan nya dengan divisi keuangan lain. Akan dibuatkan laporan keuangan mengenai Rugi dan Laba perusahaan dan laporan modal perusahaan.

Berdasarkan analisa Stakeholder yang dijelaskan, di definisikan 2 komponen yaitu aktifitas utama dan aktivitas pendukung pada suatu perusahaan untuk memahami
Stakeholder yang berperan penting dalam proses bisnis dan Stakeholder yang membantu proses bisnis berjalan dengan baik.pendefinisian Stakeholder utama dan pendukung didefinisikan sesuai dengan Gambar 6 . Valuechain Stakeholder.
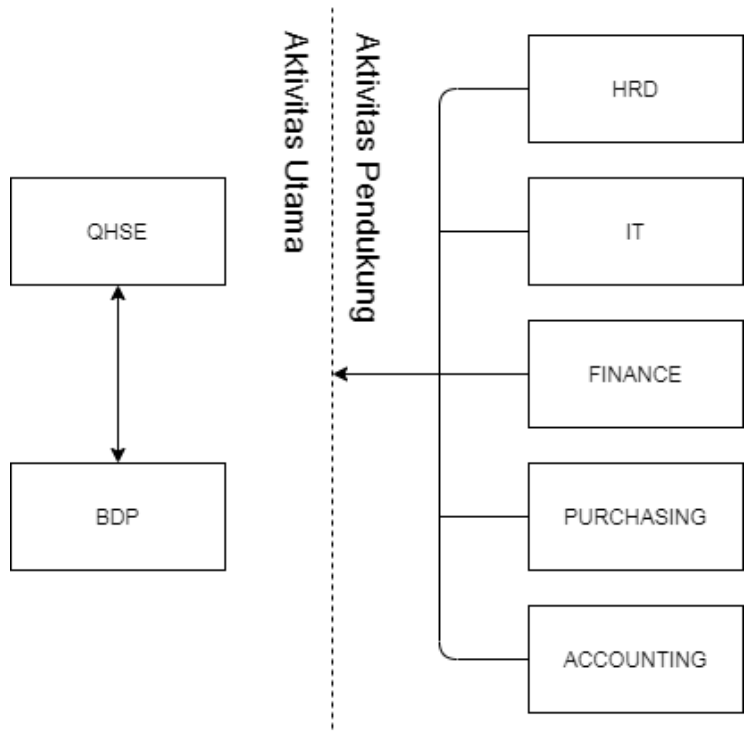

Gambar 6. Valuechain Stakeholder

Setelah menentukan Stakeholder yang terdapat pada perusahaan agar perusahaan terintegrasi dan lebih memanfaatkan Teknologi IT dalam proses bisnis. Ditentukan peran Stakeholder dan kendala yang dihadapi dalam menjalankan proses bisnis nya (lihat Tabel 1 . Stakeholder Perusahaan).

Tabel 1. Stakeholder Perusahaan

\begin{tabular}{cl}
\hline Stakeholder & \multicolumn{1}{c}{ Kendala } \\
\hline QHSE & - Penyimpanan data yang belum \\
& terintegrasi \\
& - penggunaan kertas yang terlalu banyak \\
BDP & - Kehilangan data \\
& - Review data Tender tidak tertata \\
& dengan baik \\
& -Sistem penyimpanan data tidak \\
& terintegrasi \\
Finance & - Kesalahan pencatatan dan pencocokan \\
& data \\
& - Invoice belum terorganisir \\
Accounting & - Laporan keuangan yang tidak \\
& terintegrasi satu sama lain pada divisi \\
& keuangan \\
& - Sulit nya pencarian data keuangan \\
Purchasing & - Pembayaran yang tidak terorganisir \\
\hline
\end{tabular}

Setelah mengidentifikasi aktivitas - aktivitas dan peranan Stakeholder dan kendala Stakeholder perusahaan yang dijelaskan pada table 1 selanjutnya akan dibuatkan Analysis Gap. Analysis Gap berguna untuk menjelaskan aktivitas - aktivitas yang ada pada PT.Gadingputra Samudra yang akan di bandingkan antara aktivitas - 
aktivitas saat ini dengan arsitektur target yang diusulkan yang akan di jelaskan pada Tabel 2. Analisis Gap Arsitektur Bisnis.

Tabel 2. Analisis Gap Arsitektur Bisnis

\begin{tabular}{|c|c|c|}
\hline $\begin{array}{l}\text { Aktivitas Saat } \\
\text { Ini }\end{array}$ & Rencana Aktivitas & $\begin{array}{c}\text { Analisis } \\
\text { Gap }\end{array}$ \\
\hline $\begin{array}{l}\text { Absensi secara } \\
\text { manual }\end{array}$ & $\begin{array}{c}\text { Absensi secara } \\
\text { otomatis }\end{array}$ & Replace \\
\hline $\begin{array}{l}\text { Pertemuan } \\
\text { Client yang } \\
\text { masih Eye-To- } \\
\text { Eye }\end{array}$ & $\begin{array}{l}\text { Pertemuan Client } \\
\text { dengan Chat Room }\end{array}$ & Replace \\
\hline $\begin{array}{l}\text { Pencarian Data } \\
\text { Proyek yang } \\
\text { tidak tersortir }\end{array}$ & $\begin{array}{l}\text { Sortir data proyek } \\
\text { sesuai dengan } \\
\text { tahun,nama } \\
\text { perusahaan,jasa }\end{array}$ & Replace \\
\hline $\begin{array}{l}\text { Meeting Tanda } \\
\text { Tangan Kontrak } \\
\text { secara langsung }\end{array}$ & $\begin{array}{l}\text { Meeting tanda } \\
\text { tangan kontrak } \\
\text { secara langsung }\end{array}$ & Retain \\
\hline $\begin{array}{l}\text { Review kinerja } \\
\text { instrument } \\
\text { selama proyek } \\
\text { berlangsung }\end{array}$ & $\begin{array}{l}\text { Review kinerja } \\
\text { selama proyek } \\
\text { berlangsung }\end{array}$ & Retain \\
\hline $\begin{array}{l}\text { Review SOP dan } \\
\text { Procedure } \\
\text { Secara Manual }\end{array}$ & $\begin{array}{c}\text { dengan Logbook } \\
\text { terintegrasi }\end{array}$ & Replace \\
\hline $\begin{array}{l}\text { Pengaksesan } \\
\text { procedure dan } \\
\text { SOP secara } \\
\text { manual }\end{array}$ & $\begin{array}{c}\text { Pengaksesan } \\
\text { Procedure dan SOP } \\
\text { dengan aplikasi }\end{array}$ & Replace \\
\hline $\begin{array}{l}\text { Penghitungan } \\
\text { gaji karyawan } \\
\text { secara manual }\end{array}$ & $\begin{array}{l}\text { Penghitungan gaji } \\
\text { karyawan secara } \\
\text { otomatis }\end{array}$ & Replace \\
\hline $\begin{array}{l}\text { Penyimpanan } \\
\text { invoice secara } \\
\text { manual }\end{array}$ & $\begin{array}{c}\text { Penyimpanan } \\
\text { invoice dengan } \\
\text { sistem inventory ter } \\
- \text { sortir }\end{array}$ & Replace \\
\hline $\begin{array}{l}\text { Penginputan kas } \\
\text { perusahaan ke } \\
\text { dalam buku } \\
\text { besar tertulis }\end{array}$ & $\begin{array}{l}\text { Penginputan kas } \\
\text { perusahaan ke } \\
\text { dalam buku besar } \\
\text { dengan aplikasi }\end{array}$ & Replace \\
\hline $\begin{array}{l}\text { Penyimpanan } \\
\text { faktur pajak } \\
\text { secara manual }\end{array}$ & $\begin{array}{l}\text { Sortir faktur pajak } \\
\text { berdasarkan tahun } \\
\text { atau bulan }\end{array}$ & Retain \\
\hline $\begin{array}{l}\text { Pendataan } \\
\text { anggaran } \\
\text { perusahaan } \\
\text { tanpa aplikasi } \\
\text { pendukung }\end{array}$ & $\begin{array}{c}\text { Mengunakan } \\
\text { aplikasi pendukung } \\
\text { sebagai inventory } \\
\text { pendataan }\end{array}$ & Replace \\
\hline
\end{tabular}

\section{Information System Architecture}

Fase ini bertujuan untuk membuat aristektur sistem informasi. Dalam fase ini pemodelan arsitektur terbagi menjadi 2 yaitu arsitektur data dan arsitektur aplikasi. Sebelum melakukan pemodelan arsitektur aplikasi. Aplikasi data harus diindentifikasikan terlebih dahulu setelah berhasil mengidentifikasikan arsitektur data akan dilanjutkan dengan pemodelan arsitektur aplikasi.

\section{Arsitektur Data}

Setelah mengidentifikasi proses yang mendukung dalam proses bisnis PT.Gadingputra Samudra. Pada tahap selanjutnya akan dilakukan pengidentifikasian dan pengelompokan data yang dibuat dan digunakan dalam proses tersebut.

Pada saat ini proses pendataan yang dilakukan pada PT.Gadingputra Samudra masih menggunakan aplikasi Microsoft Word, Microsoft Excel dan Microsoft Powerpoint. Dan dalam penyimpanan nya PT.Gadingputra Samudra belum memiliki sebuah Database yang berfungsi untuk menyimpan data - data yang di buat di dalam perusahaan agar mengurangi penggunaan kertas dan memberikan sistem penyimpanan yang lebih aman.

\section{Arsitektur Aplikasi}

Tabel 3. Analisa Arsitektur Aplikasi

\begin{tabular}{|c|c|c|}
\hline No & Sasaran Perbaikan & Solusi Aplikasi \\
\hline 1. & $\begin{array}{lr}\text { Adanya } & \text { fasilitas } \\
\text { untuk } & \text { membantu } \\
\text { perusahaan } & \text { dalam } \\
\text { melakukan } & \text { Meeting }\end{array}$ & 1.1 Aplikasi Chat Room \\
\hline
\end{tabular}

2. Adanya fasilitas 2.1 Aplikasi Review inventory yang Proyek BDP digunakan untuk penyimpanan data proyek

3 Penyederhanaan proses bisnis

4 Meminimalisir penggunaan kertas

\subsection{Aplikasi Pengajian}

4.1 Aplikasi Database berbasis $W e b$

4.2 Aplikasi arsip data perusahaan

4.3 Aplikasi Logbook prosedur dan SOP

5 Adanya fasilitas 5.1 Aplikasi pembuatan untuk bagian PO,RFQ,PR

purchasing dalam 5.2 Aplikasi Pengajuan melakukan pendataan pembelian

kebutuhan

perusahaan

5.3 Aplikasi Cost Calculation

6. Adanya fasilitas pada 6.1 Aplikasi pembuatan bagian Accounting PO, SO dalam memudahkan 6.2 Aplikasi pendataan dokumentasi keuangan transaksi pembelian dan penjualan

6.3 Aplikasi pendataan kas dan bank

7. Adanya fasilitas pada 7.1 Aplikasi Laporan bagian Finance Keuangan dalam memudahkan 
finance mealokasikan 7.2 Aplikasi Pembuatan dana perusahaan Faktur

Arsitektur aplikasi diidentifikasikan sesuai dengan proses bisnis perusahaan yang saat ini berjalan, kebutuhan pertukaran informasi dalam perusahaan dan kebutuhan alat bantu dalam membantu proses bisnis perusahaan, bias dilihat pada Tabel 3. Analisa Arsitektur Aplikasi.

Penyimpanan data dan pertukaran informasi pada saat ini dalam PT.GS belum berjalan dengan baik dan pada masing - masing divisi proses pertukaran informasi masih mengandalkan $E$ - Mail atau dengan alat bantu berupa Flashdisk.

Sama hal nya dengan pada divisi QHSE dan BDP sebagai proses utama dalam perusahaan divisi ini belum menerapkan sistem database dan sistem pertukaran informasi yang baik dan masih mengandalkan $E$ - Mail dan Flashdisk. Karena itu hal ini bisa menggangu proses bisnis saat ini.

Melihat aktivitas yang telah di identifikasikan akan di buatkan arsitektur - arsitektur aplikasi sebagai acuan PT.Gadingutra Samudra dalam membantu proses bisnis utama.pada table berikut ini dijabarkan arsitektur aplikasi yang di rekomendasikan kepada PT.GS.

\section{Technology Architecture}

Pada fase ini menggambarkan struktur teknologi yang dibutuhkan oleh PT.Gadingputra Samudra dimulai dari penentuan teknologi yang dibutuhkan seperti perangkat keras dan perangkat. Dan juga memperimbangkan alternatif - alternatif dalam pemilihan teknologi

Pada saat ini perangkat keras yang diggunakan pada setiap divisi menggunakan computer dengan spesifikasi yang bisa menunjang rekomendasi aplikasi yang diperlukan Teknologi yang diusulkan adalah ada nya penambahan Personal Computer yang akan digunakan sebagai Databasse dan dalam perangkat lunak yang digunakan sebagai sistem Database yaitu Aplikasi Database Management MySql

Database yang akan di implementasikan berguna untuk sistem penyimpanan data pada perusahaan yang akan terintegrasi dengan semua divisi hal ini dapat mempermudah perusahaan dalam mengurangi kertas dan menjaga data agar lebih aman. Berikut ini adalah kondisi teknologi yang telah di implementasikan pada PT.GS:

- Dalam pengaksesan internet perusahaan memakai jasa orang ketiga dan sistem yang di implementasikan masih menggunakan Wifi dan belum terintegrasi satu sama lain nya

- Sistem operasi yang dipakai oleh semua PC dalam perusahaan adalah Microsoft windows 10

- Laporan administrasi yang akan diproses masih dikirimkan melalui E-mail atau dengan Flashdisk

- Masing - masing divisi masih menyimpan data - data di dalam computer pribadi nya karena tidak ada nya Database
Melihat kondisi saat ini pengintegrasian sistem informasi di dalam perusahaan menjadi sasaran utama dalam melakukan pengembangan cetak biru yang di lakukan pada penelitian ini karena hal itu berikut ini adalah kondisi teknologi arsitektur yang diharapkan :

- Jaringan terintegrasi antara satu sama lain yang memudahkan perusahaan dalam melakukan pengiriman laporan administrasi dan juga keamanan data yang lebih baik

- Pembangunan Database yang diggunakan untuk penyimpanan data di dalam perusahaan agar data lebih tertata dengan baik dan mengurangi kehilangan data.

Tabel 4. Perangkat Keras Yang Dibutuhkan

\begin{tabular}{|c|c|}
\hline Kabel & Deskripsi \\
\hline $\begin{array}{c}\text { Kabel UTP } \\
\text { BELDEN CAT } 6\end{array}$ & $\begin{array}{l}\text { Kabel yang diggunakan untuk } \\
\text { mengintegrasikan computer divisi - } \\
\text { divisi yang akan disambungkan ke } \\
\text { database }\end{array}$ \\
\hline $\begin{array}{l}\text { RJ45 BELDEN } \\
\text { CAT5E }\end{array}$ & $\begin{array}{l}\text { Connector yang diggunakan untuk } \\
\text { menyambungkan antara kabel UTP } \\
\text { dan jaringan komputer }\end{array}$ \\
\hline $\begin{array}{l}\text { HARDDISK } \\
\text { BERKAPASITAS } \\
\text { 1TB }\end{array}$ & $\begin{array}{l}\text { Tempat penyimpanan data yang } \\
\text { diggunakan untuk Database kecil }\end{array}$ \\
\hline $\begin{array}{l}\text { SWITCH TP- } \\
\text { LINK } 5 \text { port }\end{array}$ & $\begin{array}{l}\text { Alat yang diggunakan untuk } \\
\text { menghubungkan beberapa jaringan } \\
\text { ke jaringan yang lebih besar }\end{array}$ \\
\hline
\end{tabular}

Tabel 4. Perangkat Keras Yang Dibutuhkan, memperlihatkan bahwa dalam pembelian perangkat keras harus disesuaikan dengan kebutuhan perusahaan dan perlu dilakukan penyesuaian dana pembelian agar tidak berlebihan membeli atau tidak sesuai dengan ekspetasi perusahaan. Perangkat keras yang dibeli tidak banyak dikarenakan perangkat keras di dalam kantor sudah memenuhi persyaratan karena itu hanya ada sedikit penambahan untuk pembelian kabel LAN dan konektor untuk pembuatan jaringan perusahaan. Kabel belden CAT 6 digunakan untuk penginstalan jaringan dalam perusahaan kabel cat 6 diggunakan karena memiliki kecepatan pengiriman data yang cepat dibandingkan dengan kabel cat 5 dan kecepatan internet yang stabil dalam pengaksesan internet. Dalam pemasangan jaringan dibutuhkan konektor yang berfungsi sebagai input yang diggunakan untuk ke computer atau ke Switch RJ45 CAT5E diggunakan karena harga nya yang murah dan tidak berbeda jauh dengan konektor CAT6. Harddisk berkapasitas 1TB digunakan untuk penggantian harddisk computer database yang tadi nya $250 \mathrm{gb}$ menjadi $1 \mathrm{~TB}$ hal ini dilakukan untuk memperbesar kapasitas penyimpanan data perusahaan yang disimpan dalam database agar tidak mengganti Harddisk secara berkala. Dan yang terakhir adalah Switch yang diggunakan sebagai penghubung antara computer ke server dibutuhkan 2 switch yang akan diggunakan pada bagian keuangan dan bagian QHSE dan BDP. 


\section{Opportunities and Solution}

Peluang dan solusi pada PT.Gadingputra Samudra untuk menghasilkan pemodelan arsitektur yang bertujuan untuk membuat sebuah Blueprint arsitektur yang diggunakan perusahaan sebagai acuan untuk memperbaiki atau mengimplementasi sistem saati ini dalam perusahaan

Dalam menunjang proses implementasi ada beberapa hal yang harus di perhatikan. Hal ini dilakukan untuk memperkecil resiko kegagalan dalam implementasi nya

\section{Biaya}

Pada fase ini menggambarkan struktur teknologi yang dibutuhkan oleh PT.Gadingputra Samudra dimulai dari penentuan teknologi yang dibutuhkan seperti perangkat keras dan perangkat. Dan juga memperimbangkan alternatif - alternatif dalam pemilihan teknologi.Faktor ekonomis sangat berperan Karena perusahaan harus menghitung keuntungan yang didapat dari pengimplmentasian sistem yang akan berjalan dan harus sesuai dengan biaya yang dikeluarkan.

Pada kasus pada PT.Gadingputra Samudra Sistem dan aplikasi yang dirancang perusahaan memerlukan tambahan Personal Computer yang akan diggunakan sebagai tempat penyimpanan Database dan perusahaan perlu untuk membeli atau membuat derapa aplikasi yang direkomendasikan untuk di implementasikan pada beberapa divisi di dalam perusahaan

\section{Training SDM}

Dengan sumber daya manusia yang sedikit dalam PT.Gadingputra Samudra perusahaan harus bisa memanfaatkan SDM nya sebaik mungkin agar proses bisnis berjalan dengan lancer

Karena itu setelah dilakukan nya pengimpementasian aplikasi dan sistem arsitektur dalam perusahaan. Akan dilakukan Training pada bagian - bagian divisi mengenai penggunaan aplikasi yang di implementasikan

Dalam hal ini divisi IT bertanggung jawab atas Maintenance pada aplikasi dan bertanggunga jawab dalam melakukan Maintenance pada Hardware - Hardware pendukung dalam perusahaan. Saat ini divisi IT belum dimanfaatkan dengan baik oleh perusahaan dan arah kerja dari divisi IT belum jelas akan mengarah kemana. Karena itu dengan ada nya sistem arsitektur yang baru dan pengimplemetasian aplikasi pada divisi - divisi diharapkan bagian IT mampu bekerja dengan maksimal.

Dengan mengimplementasikan sistem baru ada resiko kegagalan jika tidak di implementasikan dengan baik karena itu utuk mengutrangi resiko kegagalan sistem perlu dilakukan:

- Melakukan testing pada setiap aplikasi dan semua modul - modul nya untuk melihat suatu Bug yang ada di dalam aplikasi dan bisa segera memperbaiki nya
- Mendokumentasikan sistem informasi secara menyeluruh dengan terstruktur sehingga jika terjadi suatu kesalahan bisa di lacak dengan mudah

- Melakukan migrasi data jika ada pengimplementasian aplikasi sebelum nya

- Melakukan training pada semua bagian divisi

- Melakukan sosialisasi untuk semua Stakeholder dalam perusahaan

\section{Kesimpulan}

Berdasarkan hasil dari penelitian dari PT.Gadingputra Samudra dapat diambil kesimpulan :

1. Dengan menggunakan TOGAF ADM untuk membuat Enterpirse Architecture pada perusahaan PT.Gadingputra Samudra dapat menghasilkan perancangan sistem secara umum yang sesuai dengan visi dan misi pada perusahaan dan dapat di implementasikan pada kasus lain yang memiliki kasus yang sama

2. Dari hasil penelitian didapat beberapa arsitektur aplikasi yang didapatkan dari hasil observasi dan wawancara pada Stakeholder perusahaan yaitu pada bagian BDP didapat 1 aplikasi pada bagian QHSE didapat 1 pada bagian HRD diadapatkan 1 aplikasi untuk meminimalisir kertas didapat 3 aplikasi pada divisi Purchasing di dapat 3 aplikasi pada bagian Accounting didapat 3 aplikasi dan pada bagian Finance didapat 2 aplikasi yang akan di intgrasikan menggunakan Database

\section{Daftar Pustaka}

[1] Rianto, B., Lidya, L., \& Nurcahyo, G. W. (2016). Pemodelan Arsitektur Enterprise Menggunakan Metode Togaf ADM Studi Kasus Dinas Kesehatan Kabupaten Indragiri Hilir. Jurnal Komputer Terapan, 2(1), 55-68.

[2] Entas, S. (2016). Perancangan Arsitektur Enterprise Untuk Perguruan Tinggi Swasta Menggunakan TOGAF ADM (Studi Kasus STP Sahid Jakarta). Paradigma, XVIII(1), 67-78.

[3] https://gadingputrasamudra.com/about-our-visimisi.php (diakses pada tanggal 7 Februari 2020)

[4] Murpratiwi, S. I., Gustina, A. W., \& Dewi, I. C. (2016). Design of Enterprise Information System with TOGAF Framework ( Case Study : STD Bali ). International Journal of Engineering and Emerging Technology, 1(1), 20-25.

[5] Rizky, N., Fitroh, \& Firmansyah, A. F. (2017). Perencanaan Arsitektur Enterprise Menggunakan Togaf Adm Versi 9 (Studi Kasus: Bimbel Salemba Group). Jurnal Sistem Informasi, 10(1), 11-20.

[6] Aulia, I. N., Raharjana, I. K., \& Purbandini. (2017). Perencanaan Arsitektur Perusahaan pada Bagian Instalasi Rawat Jalan dengan Kerangka Kerja TOGAF ADM. Journal of Information Systems Engineering and Business Intelligence, 3(1), 52-60. 
[7] Fahrianto, F., Amrizal, V., \& Aenun, A. (2015). Perencanaan Infrastruktur Teknologi Informasi Di Lembaga Penelitian (Lemlit) Uin Syarif Hidayatullah Jakarta Menggunakan Togaf Architechture Development Method (Adm). Jurnal Teknik Informatika, 8(2), 1-13. https://doi.org/10.15408/jti.v8i2.2444

[8] Wibowo, F. G., Nugroho, E., Winarno, W. W., \& Mada, U. G. (2013). Kredit Dengan Menggunakan Togaf Architecture ( Studi Kasus : Badan Pemeriksa Keuangan Ri ). 6(1), 1-12.

[9] Kustiyahningsih, Y. (2013). Perencanaan Arsitektur Enterprise Menggunakan Metode Togaf Adm (Studi Kasus: Rsud Dr.Soegiri Lamongan). Prosiding Seminar Nasional Manajemen Teknologi XVIII, 1-8.

[10] Wiyana, -, \& Winarno, W. W. (2015). Sistem Panjaminan Mutu Pendidikan Dengan TOGAF ADM Untuk Sekolah Menengah Kejuruan. Register: Jurnal Ilmiah Teknologi Sistem Informasi, 1(1), 714. https://doi.org/10.26594/r.v1i1.40

[11] https://www.visualparadigm.com/guide/togaf/togaf-adm-tutorial/ (Diakses pada tanggal 7 februari 2020)

[12] Syaddad, H. N. (2015). Perancangan Model Arsitektur Sistem Informasi Di Perguruan Tinggi
Menggunakan Togaf Architecture Development Methode (Adm) (Studi Kasus: Universitas Suryakancana). Media Jurnal Informatika, 7(2). https://jurnal.unsur.ac.id/mjinformatika/article/view $/ 137$

[13] https://strategicmanagementinsight.com/tools/value -chain-analysis.html (diakses pada tanggal 9 februrari 2020)

[14] https://www.visual-paradigm.com/guide/strategicanalysis/what-is-value-chain-analysis/ (diakses pada tanggal 9 februari 2020)

[15] Riwanto, R. E., \& Andry, J. F. (2019). Enterprise Architectures Enable of Business Strategy and IS/IT Alignment in Manufacturing using TOGAF ADM Framework. International Journal of Information Technology and Business, 1(2), 1-2.

[16] Supriatna, A. (2010). Analisa Penerapan Togaf Dan Cobit Dalam Tata Kelola Teknologi Informasi Sebagai Usulan Pada Kementerian Energi Dan Sumber Daya Mineral. Seminar Nasional Informatika, 2010(semnasIF), 1-8. 